\title{
FRACTURE OF THE TIBIAL TUBERCLE IN THE ADOLESCENT
}

\author{
S. P. CHOW, J. J. LAM, J. C. Y. LEONG
}

From the University of Hong Kong

\begin{abstract}
We have reviewed 16 patients with avulsion fractures of the tibial tubercle, mostly boys who sustained left-sided injuries during sport. Two-thirds had type I or II injuries and were treated conservatively. Fractures involving the knee joint (type III) had internal fixation. The final results were good except for minor complications such as a prominent and uncomfortable tibial tubercle.
\end{abstract}

Avulsion fracture of the tibial tuberosity in the adolescent is uncommon : up to 1986,150 fractures had been reported in 145 patients (Sibley 1853; Levi and Coleman 1976; Ogden, Tross and Murphy 1980; Ogden 1982; Roberts 1984; Bolesta and Fitch 1986; Polakoff, Bucholz and Ogden 1986). There has been some concern about potential disturbance of growth and arthritic change after this injury, since the fracture involves a growth plate and occasionally involves an articular surface.

\section{PATIENTS AND METHODS}

We retrospectively reviewed the 16 patients admitted to Queen Mary Hospital, Hong Kong, with avulsion fracture of the tibial tuberosity from 1976 to 1987 . Follow-up had been for an average of 3.7 years (four months to 11 years). The fractures were classified according to the Ogden et al (1980) modification of the Watson-Jones method (Wilson 1976), based on the extent of injury and the amount of displacement (Fig. 1):

Type IA - fracture through the ossification centre of the tuberosity;

Type IB - as IA with displacement;

Type IIA - fracture-separation of the whole tuberosity;

Type IIB - as IIA with comminution of the ossification centre;

Type IIIA - fracture extending into the knee with some displacement;

Type IIIB - as IIIA with comminution.

S. P. Chow, MS, FRCS Ed, Reader

J. J. Lam, MB BS, Medical Officer

J. C. Y. Leong, FRCS, FRCS Ed, FRACS, Professor

Department of Orthopaedic Surgery, University of Hong Kong, Queen Mary Hospital, Hong Kong.

Correspondence should be sent to Dr S. P. Chow.

(C) 1990 British Editorial Society of Bone and Joint Surgery $0301-620 X / 90 / 2046 \$ 2.00$

J Bone Joint Surg [ Br] 1990; 72-B:231 -4.
I A

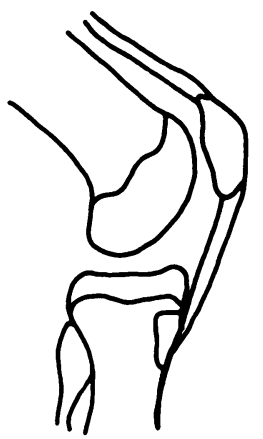

I I A

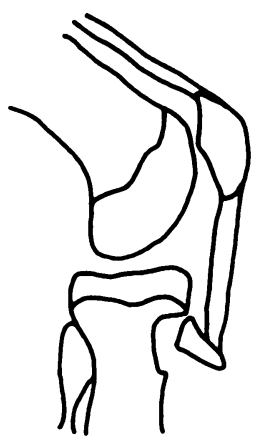

I I A

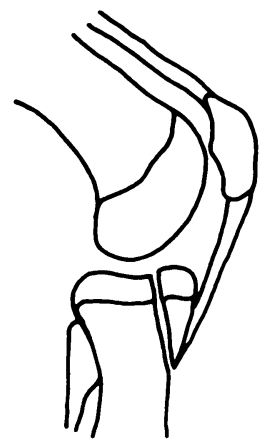

IB

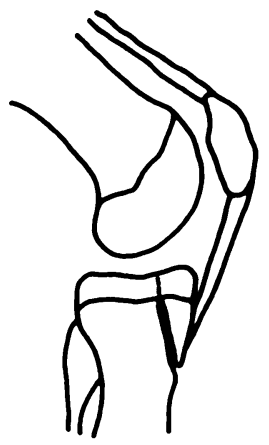

I IB

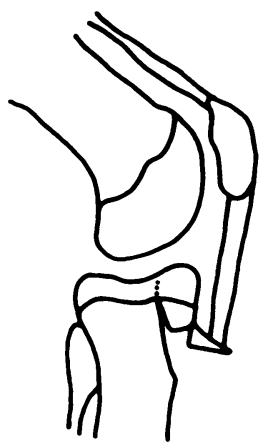

I I I B

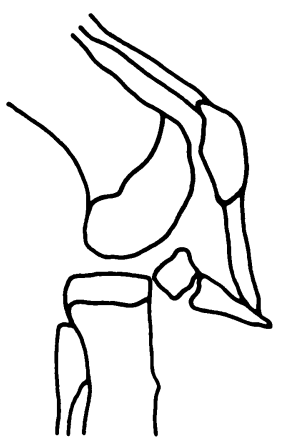

Fig. 1

Types of injury of the tibial tuberosity (Ogden et al 1980). 
Table I. Clinical details of 16 patients with avulsion fractures of the tibial tubercule

\begin{tabular}{|c|c|c|c|c|c|c|c|c|c|}
\hline Case & Sex & $\begin{array}{l}\text { Age } \\
\text { (yr) }\end{array}$ & $\begin{array}{l}\text { Mechanism } \\
\text { of injury }\end{array}$ & $\begin{array}{l}\text { Injured } \\
\text { side }\end{array}$ & Type & $\begin{array}{l}\text { Extensor } \\
\text { function }\end{array}$ & $\begin{array}{l}\text { Foll } \\
\text { yr }\end{array}$ & $\begin{array}{l}\text { low-up } \\
\text { mth }\end{array}$ & Complication \\
\hline 1 & $\mathbf{M}$ & 14 & Soccer & $\mathbf{R}$ & IA & + & 7 & 0 & Prominent tuberosity \\
\hline 2 & $\mathbf{M}$ & 15 & High jump & L & IA & - & 5 & $\mathbf{0}$ & Pain on squatting \\
\hline 3 & $\mathrm{~F}$ & 10 & Fall & $\mathbf{R}$ & IA & + & 2 & 0 & $\begin{array}{l}\text { Tender, calcified } \\
\text { patellar tendon }\end{array}$ \\
\hline 4 & $\mathrm{~F}$ & 13 & Long jump & $\mathbf{L}$ & IA & + & 0 & 6 & - \\
\hline 5 & $\mathbf{M}$ & 11 & Hurdling & $\mathrm{L}$ & IA & + & 0 & 6 & - \\
\hline 6 & $\mathbf{M}$ & 14 & Hurdling & $\vec{L}$ & IB & + & 2 & 0 & Numb below tuberosity \\
\hline 7 & $\mathbf{M}$ & 13 & $\begin{array}{l}\text { Traffic } \\
\text { accident }\end{array}$ & $\mathbf{R}$ & IIA & + & 11 & 0 & Tender over tuberosity \\
\hline 8 & $\mathbf{M}$ & 16 & Fall & $\mathbf{L}$ & IIA & + & 10 & 0 & - \\
\hline 9 & $\mathbf{M}$ & 13 & $\begin{array}{l}\text { Traffic } \\
\text { accident }\end{array}$ & $\mathrm{L}$ & IIA & + & 0 & 10 & $\begin{array}{l}\text { Posterior cruciate } \\
\text { laxity }\end{array}$ \\
\hline 10 & $\mathbf{M}$ & 13 & Running & $\mathbf{L}$ & IIA & + & 5 & 0 & - \\
\hline 11 & $\mathbf{M}$ & 13 & Running & $\bar{L}$ & IIA & + & 1 & $\mathbf{0}$ & - \\
\hline 12 & $\mathbf{M}$ & 14 & Handball & $\mathbf{L}$ & IIB & - & 3 & 0 & Numb below tuberosity \\
\hline 13 & $\mathbf{M}$ & is & Basketball & $\vec{L}$ & IIIA & - & 0 & 4 & - \\
\hline 14 & $\mathbf{F}$ & 11 & Hurdling & $\bar{L}$ & IIIA & - & 1 & $\mathbf{0}$ & - \\
\hline 15 & $\mathbf{M}$ & 14 & High jump & L & IIIB & - & 9 & $\mathbf{0}$ & - \\
\hline 16 & M & 14 & Soccer & $\mathrm{L}$ & IIIB & - & 2 & 0 & - \\
\hline
\end{tabular}

Clinica! details of the patients are shown in Table I. Thirteen of the 16 were boys; 14 patients were injured during sport and two in traffic accidents. All patients were right-handed but 13 of the fractures were on the left side. Only one patient had symptoms suggestive of Osgood-Schlatter's disease for about six months before the injury.

All patients had presented with swelling, pain, and tenderness over the tibial tuberosity. All but one of the six type I and six type II patients could actively extend the knee, the one exception had a concomitant rupture of the patellar tendon.

The 10 patients with type IA and IIA injuries (with no displacement of an articular fragment or proximal displacement of the tuberosity) were treated in plaster for about six weeks, though the ruptured patellar tendon did require surgical repair. The other six patients had open reduction and internal fixation, with plaster for about six weeks.

\section{RESULTS}

The final results were good in all patients with full range of movement and good strength. Only one patient chose not to return to vigorous sports activities. Complications, each seen in one patient, included residual discomfort over the tuberosity, pain over a calcified patellar tendon, discomfort on squatting in the patient with a repaired patellar tendon, a prominent tuberosity, and grade 1 anterior cruciate laxity. Two of the patients had residual numbness over the tibial tuberosity after open reduction, presumably due to surgical injury to the infrapatellar branch of the saphenous nerve.

\section{Illustrative case reports}

Case 2. A 15-year-old boy had a left-sided type IA fracture with avulsion of the patellar tendon and tearing of the medial retinacular fibres and capsule. At operation, the tubercle fracture was fixed with one screw and the patellar tendon was anchored slightly distal to its original insertion using an 18 gauge Bunnell pull-out wire and nylon sutures (Fig. 2). A plaster in extension with full weight-bearing was retained for six weeks, and the metal was removed at 22 months.

Over five years later he had regained a full range of movement and played basketball, but still had discomfort at the insertion of the patellar tendon in extreme flexion and especially on squatting, but this did not require active treatment. The alignment of the patellar tendon was good and there were no patellofemoral joint problems.

Case 14. An 11-year-old girl sustained a left-sided type IIIA injury during hurdling (Fig. 3a). At open reduction

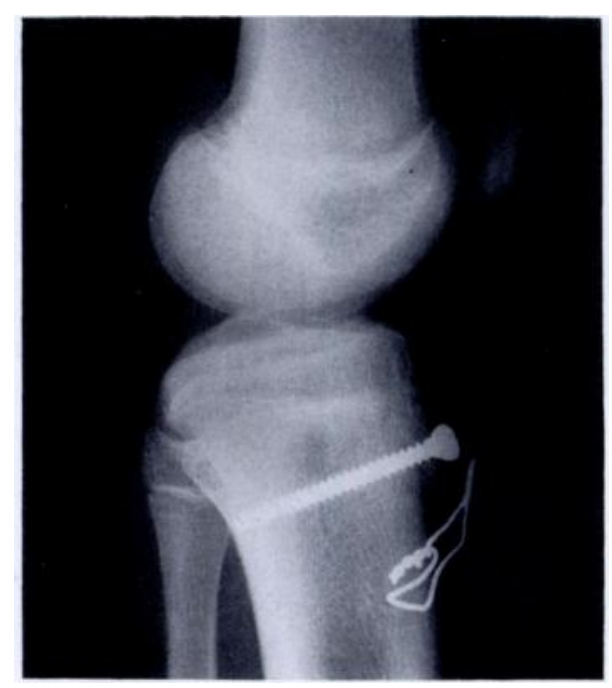

Fig. 2

Case 2. Fixation of the fracture with a screw and repair of the patellar tendon with a wire. 


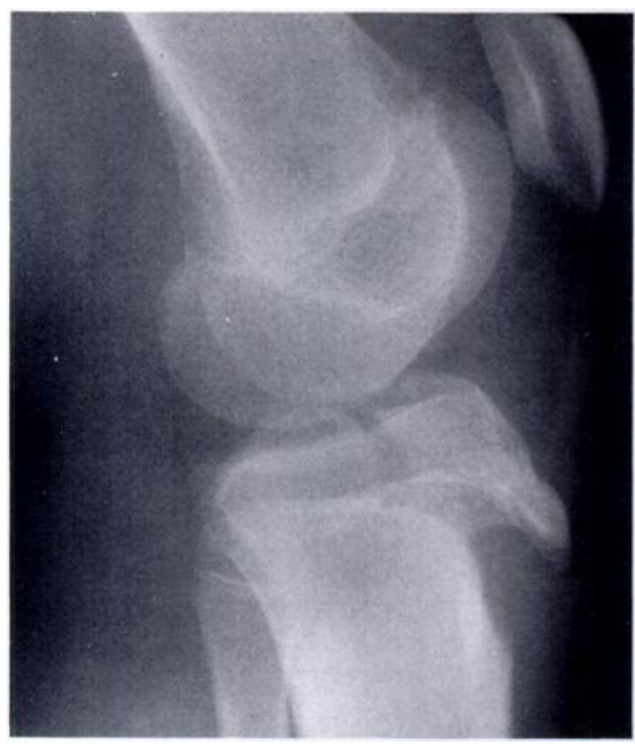

Fig. 3a

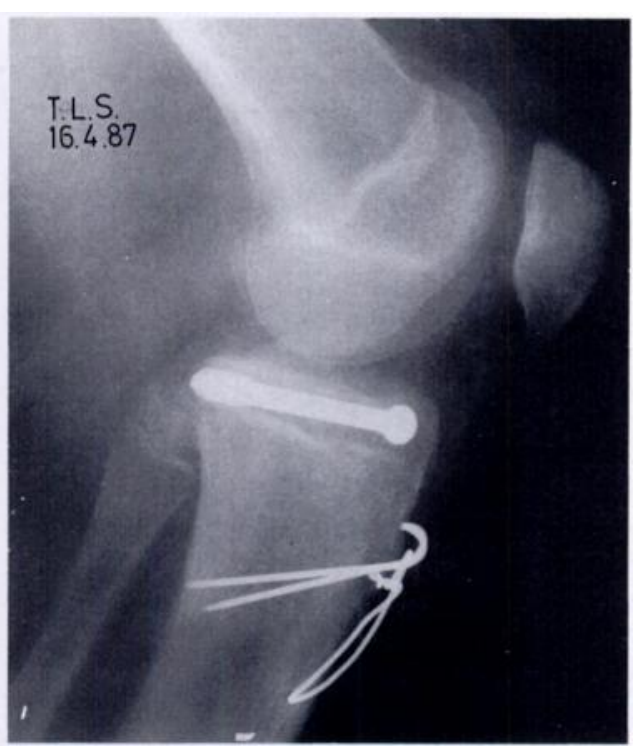

Fig. 3b

Case 14. A type IIIA fracture, showing its intra-articular extension. The postoperative film shows good reduction of the articular surface.

by a lateral parapatellar approach the articular surface was reduced perfectly with the help of an arthroscope, and a cancellous-type screw was placed in the epiphysis without damaging the growth plate. This held the perfect reduction in slight compression. Two $\mathrm{K}$-wires and a tension band were placed distally (Fig. 3b).

Continuous passive mobilisation (CPM) with gradually increasing magnitude was given for the first week, serial radiographs showing that the reduction was stable. Active non-weight bearing mobilisation was continued for six weeks, at which stage radiographs showed solid union and the implants were removed. Weight-bearing was then started, and at one year she has a full range of movement, and had resumed sport.

\section{DISCUSSION}

Our series and that of Bolesta and Fitch (1986) are the largest reported. There are some interesting findings.

Male predominance. We report only three girls and only two others have previously been reported (Levi and Coleman 1976; Ogden et al 1980). Apart from greater involvement in vigorous sport, boys have a later age for fusion of the upper tibial epiphysis (Osgood 1903; Hughes and Sunderland 1946; Ehrenborg 1962; Smillie 1978; Ogden 1984; Low and Kung 1985).

Left-sided predominance. All our patients were right handed, yet all but three sustained injury to the left knee. This preponderance on the non-dominant side is also reported in other series (Poland 1898; Christie and Dvonch 1981; Roberts 1984; Bolesta and Fitch 1986).

Relationship with Osgood-Schlatter's disease. In only one patient did we find Osgood-Schlatter's disease as a possible predisposing cause, as suggested by Ogden and Southwick (1976). Nevertheless, in this case the history was important, because the fracture was caused by a trivial injury (Polakoff et al 1986).

Treatment. The aim of treatment is to restore the extensor mechanism and where necessary, a perfect articular surface. Conservative treatment is indicated for type IA and IIA cases, provided the extensor mechanism is intact. Type IB, with good power of extension and adequate reduction of the avulsed fragment, may also be treated conservatively.

For all type III cases, most authors agree that internal fixation is needed to maintain an anatomical reduction. Henard and Bobo (1983) consider that the final choice of fixation should be made according to the specific need in each case. We agree with Polakoff et al (1986) that tension band wiring with a screw confined to the epiphysis, as in our case 14 , seems to be the treatment of choice. Compression should always be parallel to the growth plate and not across it (Clawson 1976).

Complications. Some minor complications were seen in our series, but no patient had genu recurvatum, as feared by Blount (1954) and others, even when the fracture occurred at an early age. No patient had a leg length discrepancy (Ogden et al 1980) and we saw none of the other reported complications such as loss of flexion (Christie and Dvonch 1981), non-union (Poland 1898; Gaudier 1905), skin erosion (Borch-Madsen 1955), or patella baja (Levi and Coleman 1976).

Conclusions. Avulsion fracture of the tibial tubercle is relatively rare and most cases can be treated conservatively. When surgical intervention is indicated, a cancellous screw and tension band wiring seems to be the 
treatment of choice. Though complications are rare and functional recovery is usually complete, postoperative continuous passive movement may help to hasten recovery.

No benefits in any form have been received or will be received from a commercial party related directly or indirectly to the subject of this article

\section{REFERENCES}

Blount WP. Fractures in children. Baltimore: Williams \& Wilkins:1954.

Bolesta MJ, Fitch RD. Tibial tubercle avulsions. J Pediatr Orthop 1986; 6:186-92.

Borch-Madsen P. On symmetrical bilateral fracture of the tuberositas tibiae and eminentia intercondyloide. Acta Orthop Scand 1954/ $1955 ; 24: 44-9$.

Christie MJ, Dvonch VM. Tibial tuberosity avulsion fractures in adolescents. J Pediatr Orthop $1981 ; 1: 391-4$

Clawson K. Editorial comments. Am J Sports Med 1976; 4:262-3.

Ehrenborg G. The Osgood-Schlatter lesion : a clinical and experimental study. Acta Chir Scand 1962; Suppl 288:1-36.

Gaudier. De l'arrachement de la tubérosité antérieure du tibia. Rev de Chir Par 1905; 3:305-34.

Henard DC, Bobo RT. Avulsion fractures of the tibial tubercle in adolescents. Clin Orthop 1983; 177:182-7.

Hughes ESR, Sunderland S. The tibial tuberosity and insertion of ligamentum patellae. Anat Rec 1946; 964:39-44.
Levi JH, Coleman CR. Fracture of the tibial tubercle. Am J Sports Med $1976 ; 4: 254-62$.

Low WD, Kung LS. Linear growth of the tibia in Chinese chinese. Morphol Anthropol 1985; 75:327-30.

Ogden JA. Skeletal injury in the child. Philadelphia: Lea \& Febiger, 1982.

Ogden JA. Radiology of postnatal skeletal development. X. Patella and tibial tuberosity. Skeletal Radiol 1984; $11: 246-57$.

Ogden JA, Southwick WO. Osgood-Schlatter's disease and tibial tuberosity development. Clin Orthop 1976; 116:180-9.

Ogden JA, Tross RB, Murphy MJ. Fractures of the tibial tuberosity in adolescents. J Bone Joint Surg [Am] 1980; 62-A :205-15.

Osgood RB. Lesions of the tibial tubercle occurring during adolescence. Boston Med Surg J 1903; 148:114-7.

Polakoff DR, Bucholz RW, Ogden JAS. Tension band wiring of displaced tibial tuberosity fractures in adolescents. Clin Orthop 1986; 209:161-5.

Poland J. Traumatic separation of the epiphyses. London: Smith \& Elder, 1898.

Roberts JM. Avulsion of the tibial tubercle. In: Rockwood CA, Jr, Wilkins KE, King RE, eds. Fractures in children. Vol 3. Philadelphia, etc: JB Lippincott Co, 1984:927-36.

Smillie IS. Injuries of the knee joint. 5th ed. Edinburgh etc: Churchill Livingstone, 1978.

Wilson JN, ed. Watson-Jones: fractures and joint injuries. 5th ed. Vol 2. Edinburgh, etc: Churchill Livingstone, 1976.

Sibley SW. Fracture of the tubercle of the tibia by the muscular action of the rectus femoris. Med Times \& Gazette 1853; 6:268-9. 